\title{
Recording gear-type pump acoustic signals for assessing the hydraulic oil impurity level in a hydraulic excavator transmission
}

\author{
Sergey Ivanov, Valeriya Knyazkina, and Alina Myakotnykh* \\ Saint Petersburg Mining University 2, 21 Line Vasilyevsky ostrov, Saint Petersburg, 199106, Russia
}

\begin{abstract}
Mechanization and development of mining machines increase the importance of maintenance quality of working bodies and the machines themselves. This requires implementing improvements in technical maintenance processes. Improving technical maintenance implies the implementation of condition monitored maintenance that also allows real-time monitoring of the technical status. As hydraulic oil pollution is one of the major causes of breakdowns, it is recommended to implement oil pollution monitoring methods that will allow estimating the real-time oil pollution level. Today, sampling is the most widespread method of pollution level control. This method is time-consuming and that is why there are many attempts to devise new methods of monitoring the real-time oil pollution level. One of such methods includes recording of the acoustic-emission signal. In this work, we suggested that increase in transmission oil pollution level leads to increase in acoustic-emission signal in $20-300 \mathrm{kHz}$ range. This increase in the acoustic level will indicate the pollution of oil with solid particles and alert the maintenance crew of the necessity of replacing the oil. This method allows real-time monitoring the hydraulic oil condition not associated with high labor, time, or economic costs.
\end{abstract}

\section{Introduction}

Mechanization of mining equipment sets stricter requirements for the maintenance of mining machines and their transmissions. Constant availability of mining machines is achieved by implementing more effective processes of machines and equipment maintenance $[1,2]$. The technical status of a mining machine is affected by various factors: rate of work, initial technical state, and the maintenance system applied to maintaining a machine. Every machine, therefore, requires individual assessment of its technical status that becomes possible after implementing condition monitored maintenance that provides high availability of a machine and allows carrying out the most effective real-time repair works [3]. Today, this issue is still relevant as modern hydraulic machines often break due to their hydraulic transmissions polluting. The rate of malfunctioning caused by this issue is approximately equal to $50 \%$ [2, 4].

\section{Theory research}

Specifics of functioning of hydraulic drive elements is a gradual change of element determining parameters. The available theories and methods allow TO predict the resource and reliability of elements, as well as their reduction mainly caused by contamination of the fluid. However, the issues of instantaneous assessment of contamination the hydraulic oil transmission of a mining machine have not been solved, in particular, by the value of the acoustic emission signal of friction, which requires additional theoretical and experimental research.

Hydraulic oil pollutant sources can vary $[5,6]$ thus damage inflicted on a hydraulic system can vary from insignificant to high [7,8]. Sources of contamination enter the hydraulic system both from the external environment and during wear of parts. External sources of contamination are water, industrial dust, welding scale, which remains on the surface of the product. The last source is the most dangerous, since quartz particles have the most negative effect on the kinematic pairs of the hydraulic system, since their hardness is higher than the hardness of the material of which the parts are made. Contamination particles from the operation of the hydraulic system gradually destroy the product, which produces chips, cracks and wear particles that also contaminate the working fluid and lead to the aging of the fluid itself. The main type of wear for mining machines is abrasive wear, which applies not only to the working mechanisms of open type, but also closed, because the particles of pollution get through the leaks in the gearboxes, gear boxes, seals of shafts, joints, etc. [10]. Industrial dust enters the machine housing during operation due to the heating of parts, at this point the liquid liquefies and leaks through the leaks of various kinds, and after the cooling of the housing parts creates a vacuum, due to which the industrial dust particles enter the machine together with the air.

\footnotetext{
* Corresponding author: alinamyakotnyh@yandex.ru
} 
Failures described above can be prevented by hydraulic oil real-time pollution level control [9, 10]. As of today, hydraulic oil pollution level assessment is performed through sampling [6] which is timeconsuming itself and requires carrying out complex laboratory tests. Nevertheless, there are studies that show the possibility of assessing the hydraulic oil pollution level in real-time. Sampling went to a new level in one of the research papers [11], where researchers described 'drop sampling', i.e. automatic oil sampling and optical analysis of the samples. This method realizes similar methods described in research [12]. In the paper [13], the authors presented a combined method of oil condition assessment that includes optical analysis and dielectric permeability assessment similar to [14]. Apart from the methods described above, photography equipment is also a widespread means of assessing the oil condition and pollution level [15]. This equipment allows analysing the number and size of solid particles. Solid particles polluting oil in hydraulic transmissions can have environmental nature, e. g. when a machine is working in a dusty environment, and get inside the mechanism through filters, tightenings, and valves, or can be a product of transmission elements and units wear off [16, 17]. It is also worth noting that in laboratories, the oil pollution level is often analysed with the use of spectral analysis [18, 19] and the assessment of quantity and quality of acoustic signals [20].

The acoustic emission method allows one to obtain real-time information about the state of the controlled object by recording and analyzing acoustic emission, which accompanies the processes of restructuring of a solid body, outflow of liquid media and friction of surfaces. Due to a wide range of actions, this method provides an opportunity to assess the technical condition of working bodies and fluids. The possibility of detecting phase transitions, registration of friction surfaces, impacts in the object, etc. Assume the probability of using the method of acoustic emission to assess the condition of the transmission fluid.

The research presented in this work is aimed to show that acoustic signal recording allows real-time determining oil pollution levels at a sufficient accuracy. We suggested that an increase in transmission oil pollution level results in acoustic signal quantity increase, thus allowing us to estimate the level of oil pollution.

\section{Materials and methods}

For experimental needs, a special-purposed test bench was assembled, its construction included a throttleable hydraulic open circuit, a pump point with an NSh-10 gear-type pump; pressure gauge; gear-motor drive UDD $1050 \mathrm{M}$ with an adjustable rotation rate; a 0.005 $\mathrm{m}^{3}$ container with TAD-17i oil, TCh10-R tachometer hour, a magnetic sensor for acoustic signal registration mounted on the pump body at a point of gears contact; and Metatkom ARP-11, an ultrasound acoustic-emission equipment life analyzer with a working range of 20-300 khz.

In order the actual energy consumption to estimate when the speed mode of the geared motor change, a preliminary calibration was carried out. The first experimental session included test bench gauging aimed at assessing real parameters of gear-motor driveshaft rotation rate and determining real power consumption in course of gear-motor rate adjustment. It was determined that fixed values of driveshaft rotation speed were: $30.89,35.34,40.97,53.8$, and $60.2 \mathrm{rad} / \mathrm{s}$, which correspond to the switch positions $1 ; 3 ; 5 ; 7 ; 9$; and 11 on the geared motor housing, respectively.

Then we tested shifts in acoustic signals emitted by frictions in gear-pump rotary group during TAD$17 \mathrm{i}$ oil circulation throughout throttleable circuit in no-load conditions and under 0.2-0.4 MPa pressure. Acoustic signals changes were registered in acousticemission range. In order to acquire reference values, initial tests were performed with the use of unpolluted oil. During the following sessions, the oil was incrementally polluted with $20 \mathrm{~g}$ of electrocorundum added to each consecutive session up to a $1 \%, 2 \%$ and $3 \%$ oil pollution level. During the first session, the abrasive material with $40 \mu \mathrm{m}$ particles was applied, while during the second session, we used the abrasive material with $100 \mu \mathrm{m}$ particles. It was decided to measure each parameter 3 times, due to repeated values, averaging them. Further, the results are required to compare relative to the reference value and each other.

\section{Results and discussion}

The data acquired during tests were processed and presented as graphs. To understand the results of our tests, it is sufficient to demonstrate the dependency of the acoustic signal value on the driveshaft rotation speed in the case when the oil is polluted with $40 \mu \mathrm{m}$ solid particles (figs. 1 and 2). It is also worth mentioning how the particle size affects the quantity of the acoustic signal (figs. 3 and 4).

In fig. 1 and fig. 2 , there is an obvious difference between acoustic signal parameters, moreover, the figures show that with increasing oil pollution level acoustic signal parameter is also increasing. Under the 0.2-0.4 MPa pressure we observe increased parameters in comparison with the parameters registered in no-load conditions. At equal speeds, the values of the acoustic signal parameter increase with increasing contamination.

Figs. 3 and 4 show the same dependency on the load and also demonstrate that the size of particles affects the acoustic signal - the larger the size of particles, the higher acoustic signal values are. This results from the integral $\mathrm{D}$-value nature that depends directly on friction force. Particles of a greater size will result in higher force generated in points of gears 
contact of the NSh-10 pump and, therefore, in higher acoustic signal values.

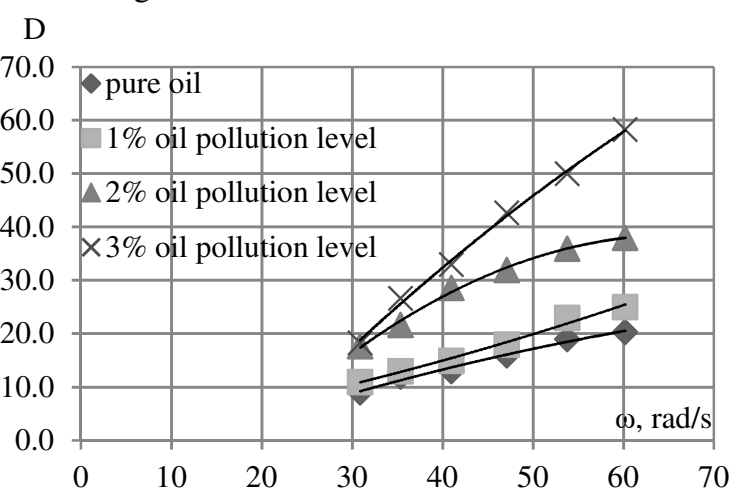

Fig. 1. Dependency of integral friction value D on NSh-10 pump driveshaft rotation speed in no-load conditions

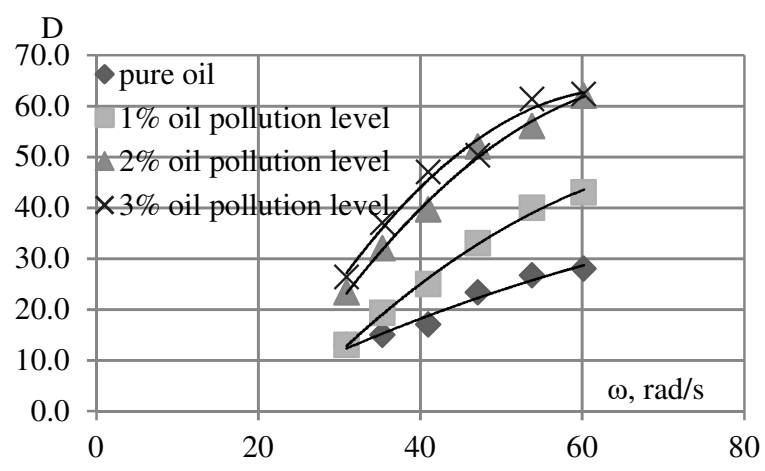

Fig. 2. Dependency of integral friction parameter D on NSh-10 pump driveshaft rotation speed when 0.2-0.4 MPa pressure is applied

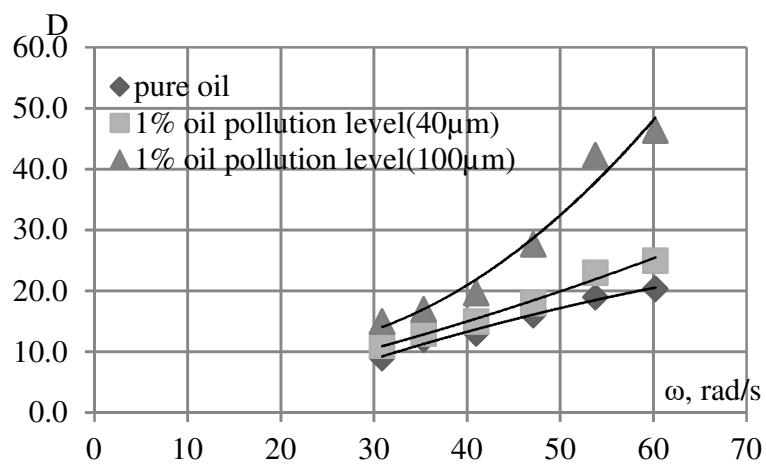

Fig. 3. Comparison of D-values in no-load conditions

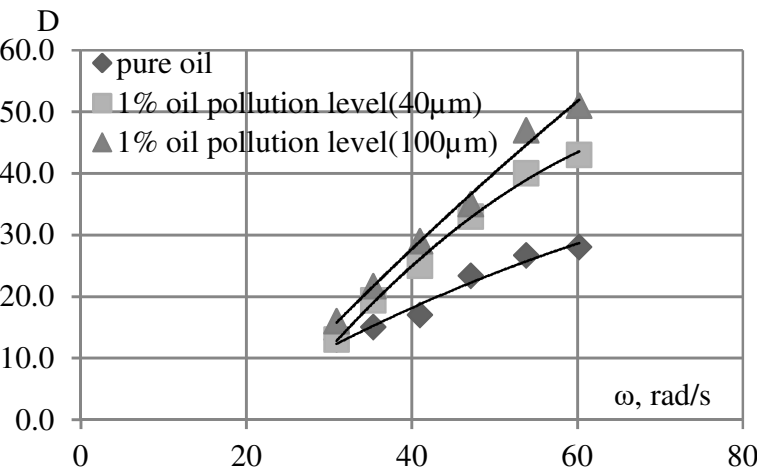

Fig. 4. Comparison of D-values when 0.2-0.4 MPa pressure is applied

In Fig. 5 and Fig. 6 shows the dependence of the acoustic emission index on the contamination of the working fluid at idle running and at a load of 0.2-0.4 $\mathrm{MPa}$. The obtained graphs clearly show how the acoustic emission signal increases with increasing contamination of the fluid, both with and without load in the hydraulic channel.

This dependence allows you to determine the concentration of contamination of the fluid on the acoustic emission signal indicator. Knowing the values of the acoustic emission parameter, which are registered by the sensor, you can determine the value of contamination of the fluid through the tangent of the slope of the constructed curve

Based on this study, a device has been developed for assessing the contamination of the transmission fluid [11]. Application of this device will make it possible to evaluate the fluid of the transmission in real time, thus confirming the possibility of creating an on-board system for assessing the contamination of the fluid of the transmission for mining machines. It is designed to determine the rapid assessment of the contamination of the working fluid at any time, improvement of this invention will allow to carry out an onboard assessment of the contamination of the working fluid, the process of which can be observed by the operator in the cab of the mining machine.

Therefore, the contamination of the fluid medium assess at any time does not require significant labor input, as the entire process takes place with minimal participation of the operator, and the device layout with a small number of moving elements and the presence of a special algorithm in the measurement comparison unit, as well as the prompt output of the results extends the information capabilities of the device. This device is applicable to both hydraulic and mechanical transmissions, creating variations in the assembly of the device, leaving the essence and principle of operation, its application is possible on various technological machines. 


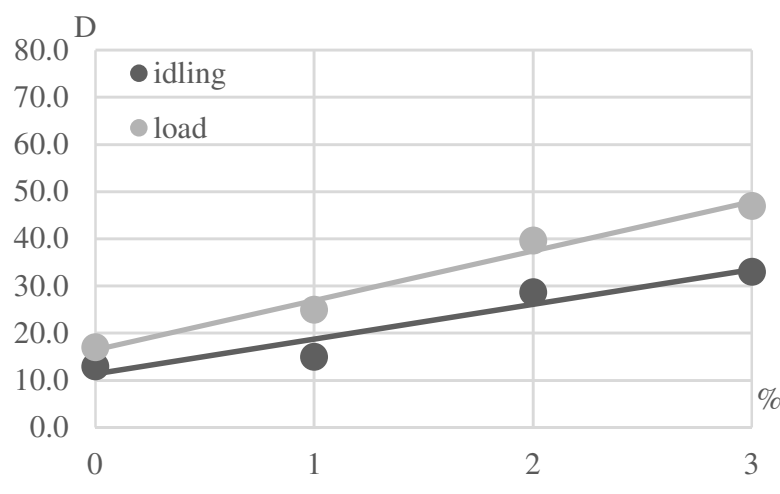

Fig. 5. Dependence of the D parameter on the concentration of contamination of the working fluid at the abrasive size of $40 \mu \mathrm{m}$ at idling and at a load of 0.2-0.4 MPa

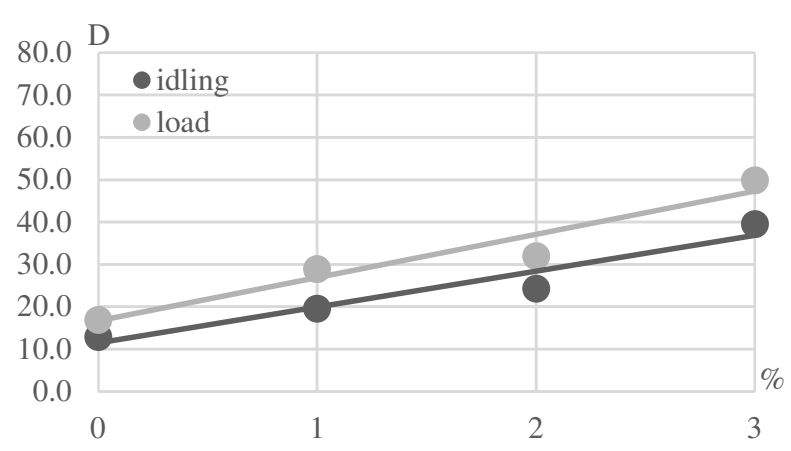

Fig. 6. Dependence of the D parameter on the concentration of contamination of the working fluid at the abrasive size of $100 \mu \mathrm{m}$ at idling and at a load of $0.2-0.4 \mathrm{MPa}$

\section{Conclusion}

Acoustic signal monitoring in the acoustic-emission range allows detecting solid particles in oil used in hydraulic transmission. Thus, the method can be applied during the express testing of the oil pollution level or it can be further implemented in an automatic diagnostic system.

Implementation of an automated system for oil pollution level control in mining machines with a hydraulic transmission will allow changing the approach to maintaining the equipment from preventive to the condition monitored one.

Taking into account that the acoustic signal quantity, registered by an acoustic sensor, is growing along with the concentration of polluting solid particles increase, hydraulic oil should be replaced upon exceeding the acceptable acoustic signal level.

An acceptable level is specific for each transmission, the base level is determined during tests with clean hydraulic oil. Knowing a slope of acoustic pressure change, it is possible to assess the condition of the hydraulic oil by measuring the extent of acoustic pressure increase $\Delta$ equal to the ratio of the slope angle to the acceptable pollution level: $\Delta=$ $\operatorname{tg} \alpha /[\%]$.

The introduction of this research methodology does not exclude the presence of basic methods of assessing the contamination of the fluid, such as sample analysis to determine the chemical and physical composition of the fluid. A comprehensive approach to assessing oil contamination will increase the life of the fluid and working bodies of hydraulic mining machines, reduce the cost of purchasing fluid for hydraulic systems, as well as improve the skills of the operating personnel, the operator of the mining machine in particular.

\section{Acknowledgments}

This study was carried out in St. Petersburg Mining University with the equipment provided by research officers from the university.

\section{References}

1. I N Antonenko, I E Kryukov, Chief Power Engineer. Automation 10, 37, (2011)

2. E V Pumpur, Devices, Aggregates and Processes. Design, Creation and modernization: Materials of the International Scientific and Practical Conference of the SPbF SIC MS,155, (2018)

3. D A Shibanov, Mining informational and analytical bulletin' 10, 86, (2020)

4. S U Kuvshinkin, I E Zvonarev, P V Ivanova, Journal of Physics: Conference Series 1118(1), 012054, (2018)

5. A $\mathrm{V}$ Punin, E G Ryljakin, Engineering journal of Don 1(3), (2015)

6. Yu Olt, Journal of Mining Institute 235, 70, (2019)

7. S Yu Zubkova, ChemTech 9, 22, (2018)

8. V V Ostrikov, V S Vjazinkin, A V Zabrodskaja, Tractors and Agricultural Machinery, 4, 18, (2019)

9. Yu D Shevtsov, L N Dudnik, L M Kritskaya, A M Nikiforov, Scientific works of the Kuban State Technological University 3, 462, (2018)

10. O A Chokubaev, Selected Speaker Papers from 62nd University Scientific Technical Conference for 
Students and Young Researchers, 505, (2016)

11. S L Ivanov, A A Myakotnykh, K A Safronchuk, V I Knyaz'kina RU Patent 2739147 Device for Evaluation of Contamination of Fluids of Transmissions (21 December 2020)

12. B G Salatov, Proc. Int. Conf. Dedicated to the 90-th Anniversary of E.P. Ogry 'zkova FSBEI HE Omsk State Agrarian University, 257, (2019)

13. I A Nechaeva, Education. The science. Production: Proc. Int. Forum X Belgorod 01-15 October 2018, 1731, (2018)

14. V V Semenov, Engineering journal of Don 4(51), 35, (2018)

15. A B Grigorov, E`nergosberezhenie. E`nergetika. E`nergoaudit. 11 (93), 18, (2011)

16. T Bley, E Pignanelli, A Schutze, J. Sens. Sens. Syst. 3, 121, (2014)

17. $\mathrm{K}$ O Sergeev, Bulletin of the Astrakhan State Technical University. Series: Marine Engineering And Technologies 1, 13, (2020)

18. V M Kotorash, Aircraft engineering and Transport in Siberia. XI Conf,. Irkutsk 27-28 November, 124, (2018)

19. A D Kozlova, Mechanics of the XXI Century 18, 93, (2019)

20. A G Syrkov, Journal of Physics: Conference Series, 729(1), 012026, (2016) 